\title{
The impact of the EXIST Business Start-up Grant on corporate growth: A group comparison for Dresden (GER)
}

Introduction
The EXIST Business Start-up Grant (BSG) is one of the most important govern-
mental programs in Germany to support founders by turning their business
idea into action. This paper investigates the start-ups' corporate development
using a peer group comparison on longitudinal data.
Research Question
Do BSG-funded start-ups outperform non-funded industry peers in terms of:
(i) Risk of cessation
(ii) Survival time
(iii) Employment (FTE) development
(iv) Revenue development
Keywords
- corporate growth, governmental start-up assistance, innovation policy,
Confitudinal analysis, peer group comparison
- Leading edge concepts, tools and methods to assess impact of R\&l policy
- Effects of and policy learning from impact evaluation
Acknowledgement
- Cornelia Ernst, Dresden University of Technology
- Marco Rösler, dresden | exists

\begin{tabular}{|c|c|c|c|c|}
\hline \multicolumn{5}{|c|}{ Methods } \\
\hline \multicolumn{5}{|c|}{$\begin{array}{l}\text { Data set } \\
\text { The self-collected dataset was created by conducting desk research and field research (online survey) due to a lack of reliable } \\
\text { and publicly accessible longitudinal micro-level data at the time (2017). }\end{array}$} \\
\hline \multicolumn{5}{|c|}{ 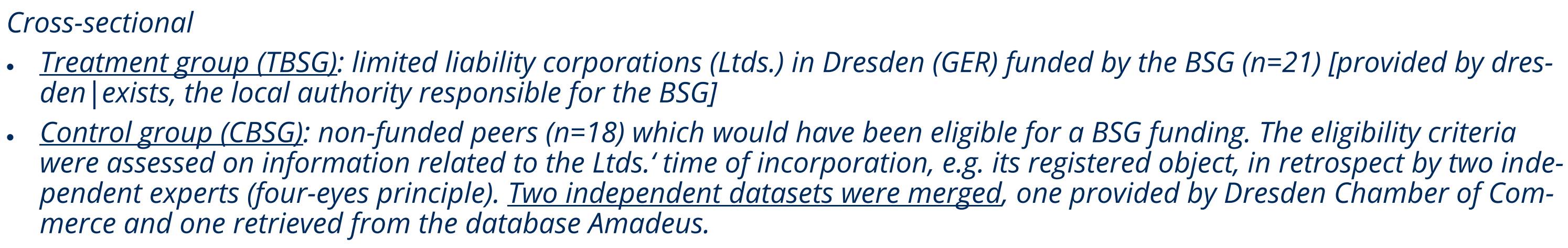 } \\
\hline \multicolumn{5}{|c|}{$\begin{array}{l}\text { Longitudinal } \\
\text { - Period of incorporation: } \\
\text { - Observation period: }\end{array}$} \\
\hline Measurement & (i) Risk of cessation & (ii) Survival time & (iii) Employment development & (iv) Revenue development \\
\hline \multirow{2}{*}{ Method } & \multicolumn{4}{|c|}{ Analysis of Differences } \\
\hline & $\begin{array}{l}\text { Cox proportional ha- } \\
\text { zards resgression }\end{array}$ & Survival time analysis & Two-way Analysis of variance & $\begin{array}{l}\text { Cumulative odds ordinal } \\
\text { logistic regression }\end{array}$ \\
\hline Variables & $\begin{array}{l}\text { Survival time } \\
\text { by Treatment }\end{array}$ & $\begin{array}{l}\text { Survival time } \\
\text { by Treatment }\end{array}$ & $\begin{array}{l}\text { Treatment and Year on FTE, } \\
\text { Treatment and Industry on FTE }\end{array}$ & $\begin{array}{l}\text { Revenue by Treatment, Industry, } \\
\text { and Year }\end{array}$ \\
\hline Specification & $\begin{array}{l}\text { - Log-rank test } \\
\text { Scaled Schoenfeld resi- } \\
\text { duals }\end{array}$ & $\begin{array}{l}\text { - Kaplan-Meier survival } \\
\text { curves }\end{array}$ & $\begin{array}{l}\text { : Type III sums of squares } \\
\text { Bonferroni adjustment }\end{array}$ & $\begin{array}{l}\text { - Proportional odds } \\
\text { Post-estimation: discrete and } \\
\text { marginal change }\end{array}$ \\
\hline
\end{tabular}

\section{Results}

(i) Risk of cessation

Visual inspection of proportional risk of cessation (Figure 1) is inconclusive because the curves cross each other but lie in the same range overall. However, the result of a performed log-rank test $(p=.820)$ provides evidence that the survival distributions of the two groups are not statistically different. This is supported by a tes

(ii) Survival time

Is almost equal (Table 1) between the two groups which blends into the result of almost equal risk of cessa-

(iii) Employment development

Related to employment overall, Wilcoxon's two-sample rank sum test (Table 1) provides evidence to negate an overperformance by funded Ltds., which is displayed in Figure 2. On the contrary, groups' means indicate For employment development, the results of Analyses of Variance are ambiguous and highly effected by outliers which is depicted in Figure 2. Over or underperformance of funded Ltds. depends on the industry sector.

Related to revenue overall, independent t-test (Table 1) provic

Moreover, there are higher probabilities of generating higher revenue for control peers.

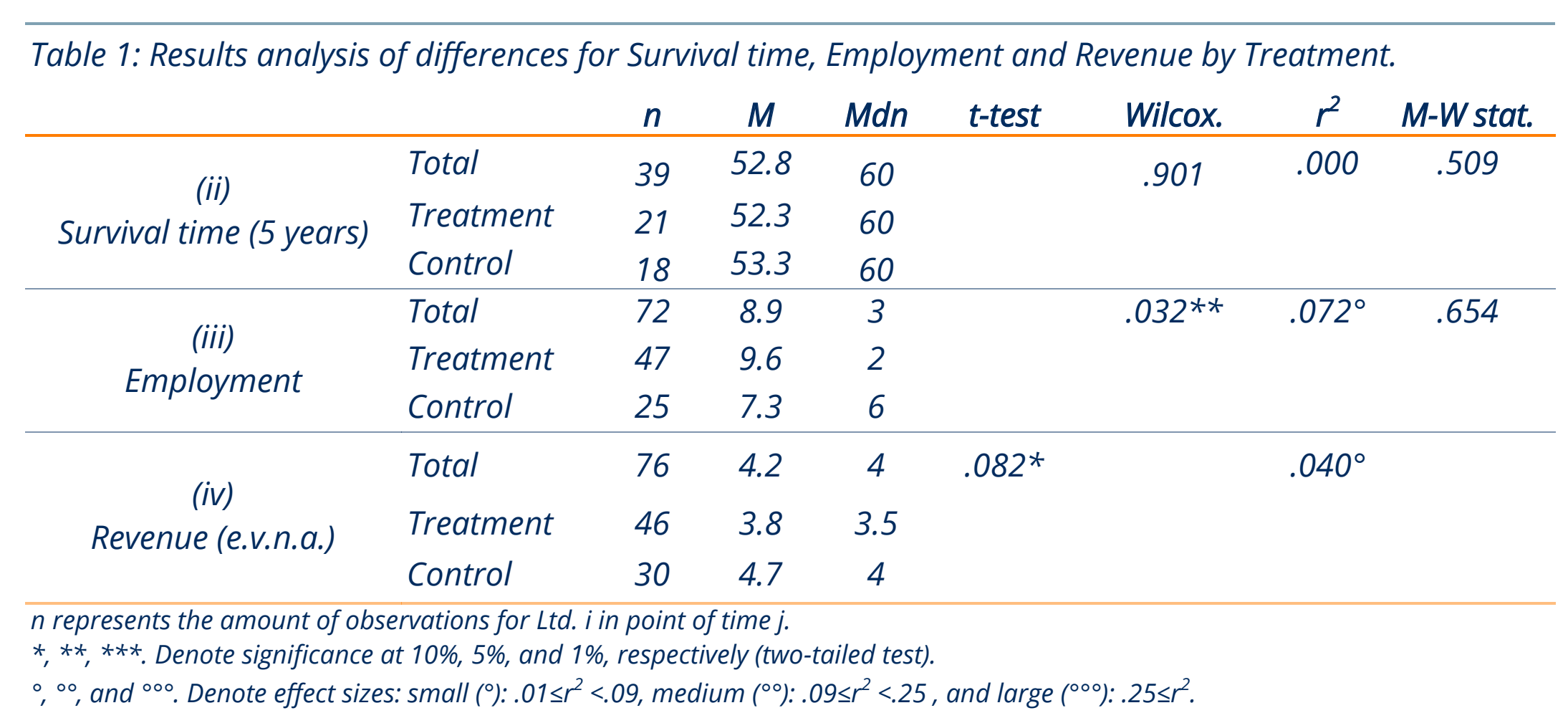

\section{Conclusion and Policy recommendation}

Funded Ltds. do not outperform industry peers in terms of (i) risk of cessation and (ii) survival time.

Rather non-funded industry peers perform better than funded Ltds in terms of (iii) employment and (iv) revenue development

According to the online survey, for 8 out of 11 respondents it would have been unlikely or even very unlikely having founded without the BSG funding. So, treatment and control groups' Ltds. might differ in their pretreatment willingness to incorporate.

The BSG in Dresden might not fund the founders ready to fly high, as intended, but helps start-up seeds to see the light of the day, which tally with the "theory of external assistance as the support option of last re
sort" (Juita-Elena (Wie) Yusuf 2017).

Policy recommendation

1. The start-up agents responsible for the BSG funding should increase active sourcing in order to not rely on the people who come in and apply for a BSG funding.

2. BSG funding might provide even more guided preparation during the one year funding period with regard to the "theory of outside assistance as a knowledge resource" by Chrisman and McMullan (2004). 3. Funded Ltds. should be encouraged to self-reliance by loosening university-related ties since proximity to uni-
versity is not necessarily related to better performance of the start-ups (Doutriaux 1987).
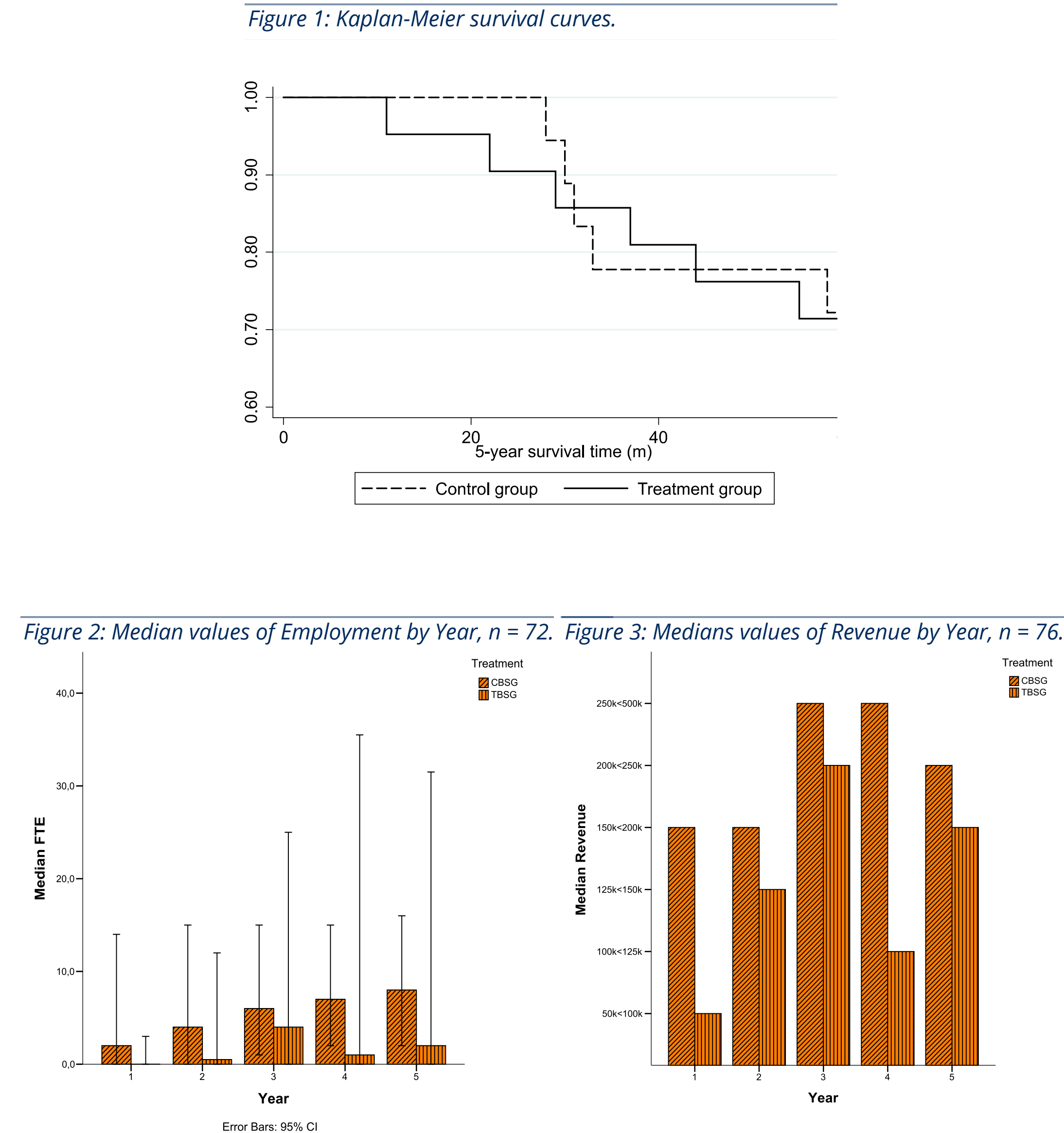

\section{Limitation and Further research}

Group sizes of 21 and 18 companies do not meet the self-proclaimed sample size
threshold of $n>30$, with regard to Student's t-distribution and the associated t-test. The results are not representative for Germany and must be interpreted even for the case of Dresden with caution.

Further research

1. Replicating on a larger sample size to meet the threshold of $n=30$, at least.

2. Detecting peers with another method, e.g. text mining the companies' object, to certify

3. Verifying the same pre-treatment conditions for the two groups to justify the matching. 4. Conducting qualitative analysis to investigate the reasons for the corporations' devel-

5. Taking advantage of variables from the self-collected dataset, which are not considered in this paper already, e.g. Year of incorporation.

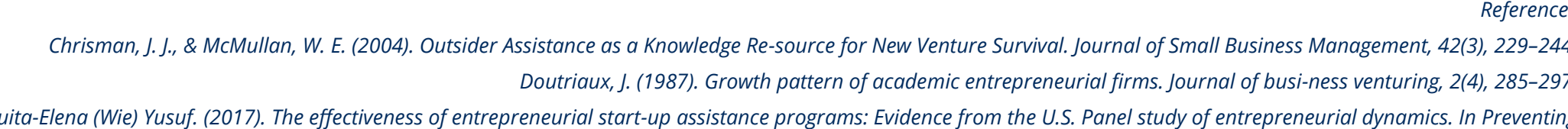

